\title{
ANALISIS PENGARUH PENAMBAHAN BIOETHANOL PADA BAHAN BAKAR MINYAK TERHADAP KONSUMSI BAHAN BAKAR SEPEDA MOTOR HONDA VERZA 150 CC (FUEL INJECTION)
}

\author{
Miftakhul Khusna*, Tabah Priangkoso dan Darmanto \\ Jurusan Teknik Mesin, Fakultas Teknik, Universitas Wahid Hasyim \\ JL. Menoreh Tengah X/22, Semarang 51585, Indonesia \\ *Email: miftakhulkhusna43@gmail.com
}

\begin{abstract}
Abstrak
Kenaikan harga bahan bakar minyak (BBM) menyebabkan pengguna kendaraan harus melakukan penghematan konsumsi bahan bakar. Pengendara kendaraan bermotor atau pengendara mobil perlu mengetahui jumlah konsumsi BBM pada tiap kecepatan, posisi gigi percepatan, dan jenis bahan bakar agar kendaraan dapat bekerja pada efisiensi yang paling bagus. Penelitian ini bertujuan untuk mengetahui pengaruh pencampuran bioethanol terhadap konsumsi bahan bakar pada sepeda motor, menggunakan Honda Verza 150 FI dengan bahan bakar Premium, Pertalite, Pertamax, dan Pertamax Turbo dan variasi campuran bioethanol 8\%, 10\%,12\%. Penggunaan jenis bahan bakar, posisi gigi, dan peningkatan kecepatan mempengaruhi konsumsi bahan bakar Pertamax Turbo murni, rata-rata pada semua gigi percepatan mampu menempuh jarak 51,70 Km/L. Pada Pertalite penambahan bioethanol $10 \%$ menempuh jarak paling jauh $85,8 \mathrm{Km} / \mathrm{L}$ dari 16 variasi bahan bakar yang diuji.
\end{abstract}

Kata Kunci: bioethanol, jenis BBM, kecepatan, laju konsumsi BBM, posisi gigi.

\section{PENDAHULUAN}

Konsumsi BBM merupakan hal penting yang harus diketahui oleh pengendara sepeda motor. Laju konsumsi BBM dapat disebabkan oleh 4 aspek yaitu aspek kendaraan, aspek lingkungan, aspek pengemudi, dan aspek kondisi lalu lintas. Faktor pertama yang ada dalam lalu lintas yaitu kecepatan kendaraan, jumlah kendaraan berhenti atau mengerem, dan kendaraan melakukan percepatan yang dilakukan pengendara. Pada aspek lingkungan sekitar di dalam berkendara yang dapat mempengaruhi jumlah konsumsi bahan bakar pada kendaraan adalah kemiringan (tanjakan) jalan, keadaan angin yang berembus, suhu udara, ketinggian, beberapa bentuk permukaan jalan (aspal, beton, tanah liat, paving block), \& bentuk permukaan jalan (kasar, basah, dan kering) (Priangkoso, 2014).

Apabila ditinjau dari segi jenis kendaraan, pengaruh konsumsi bahan bakar oleh berat keseluruhan kendaraan, dimensi mesin, jenis mesin (yaitu mesin bensin, mesin diesel, listrik, hibrid), bentuk transmisi, bentuk dan dimensi ban, kondisi tekanan udara di dalam ban, roda satu dengan yang lainnya, keadaan sistem pengereman dan pengapian, suhu mesin, kekentalan oli pelumas, nilai oktana pada bahan bakar yang digunakan, bentuk penampang kendaraan, dan pemakaian alat tambahan seperti pemakaian pendingin udara atau $\mathrm{AC}$, audio, dan alat pendukung lain. Dan jika dilihat dari aspek pengemudi, keefisiensian konsumsi BBM dikarenakan perilaku pengemudi di dalam berkendara, contohnya dalam menentukan kecepatan atau memilih pada percepatan. Analisis hubungan antara laju konsumsi BBM terhadap kecepatan yang dilaksanakan pada jenis kendaraan bermotor penumpang menunjukkan hasil yang serupa yaitu pada laju banyaknya konsumsi BBM lebih tinggi pada kecepatan rendah dan konsumsi BBM akan menurun dengan adanya peningkatan posisi gigi percepatan dan kecepatan kendaraan, setelah melewati titik batas kecepatan tertentu laju konsumsi BBM naik seiring dengan penambahan kecepatan kendaraan.

\section{METODE}

Analisis pengaruh penambahan bioethanol pada bahan bakar Pertalite, Pertamax dan Pertamax Turbo terhadap performa dan laju konsumsi BBM sepeda motor Honda Verza $150 \mathrm{cc}$ ini dilaksanakan dengan urutan sebagaimana terlihat pada gambar 1. Sebelum melakukan penelitian dilakukan studi literatur mengenai pengaruh luas penampang, dan beban jalan untuk menentukan hambatan udara pada laju kendaraan terhadap konsumsi bahan bakar. 
Peralatan yang digunakan untuk mengetahui konsumsi bahan bakar dan kinerja sepeda motor tersebut digunakan beberapa alat antara lain:

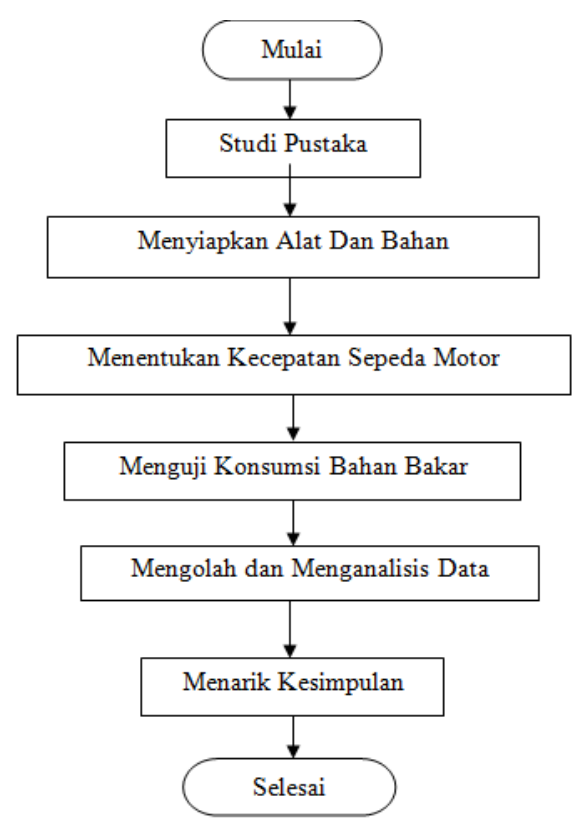

Gambar 1. Flow Chart Penelitian

\section{Mesin Uji}

Dalam penelitian ini digunakan Honda Verza $150 \mathrm{cc}$ bertransmisi manual.

\section{Bahan bakar}

Bahan bakar yang digunakan dalam penelitian ini adalah premium, Pertalite, Pertamax, dan Pertamax Turbo, dan bioethanol.

\section{Alat Uji}

Chasis dynamometer, tachometer, buret, gelas ukur, tangki bahan bakar, pompa bensin, dan selang

\section{HASIL DAN PEMBAHASAN}

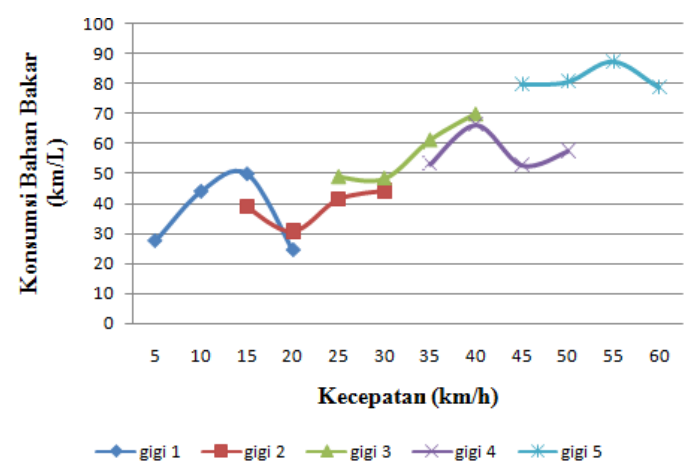

Gambar 2. Konsumsi Bahan Bakar Premium Murni
Pengujian konsumsi bahan bakar terhadap sepeda motor VERZA 150 cc FI bertransmisi manual dilakukan dengan menggunakan 4 jenis bahan bakar produk Pertamina (Premium, Pertalite, Pertamax 92, dan Pertamax Turbo) yang dicampur dengan bioethanol 8\%, 10\%, dan $12 \%$.

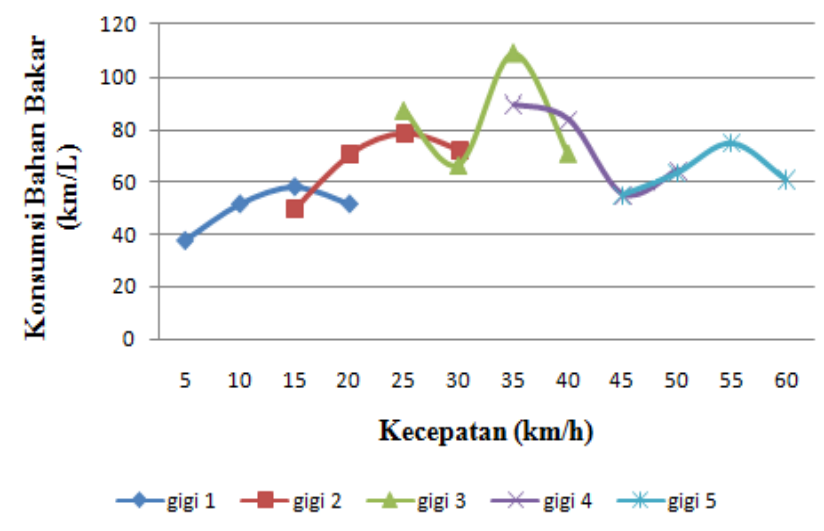

Gambar 3. Konsumsi Bahan Bakar Premium + Bioethanol 8\%

Dari data hasil pengujian didapat grafik konsumsi bahan bakar Premium dan Premium campuran dapat disimpulkan bahwa bahan bakar Premium murni, rata-rata pada semua gigi percepatan mampu menempuh jarak $54,38 \mathrm{Km} / \mathrm{L}$, jarak yang ditempuh lebih pendek dibandingkan dengan ketiga bahan bakar Premium campuran dengan konsentrasi campuran $8 \%, 10 \%$, dan $12 \%$ bioethanol per liter Premium berturut-turut yaitu 67,51 $\mathrm{Km} / \mathrm{L}, 70,42 \mathrm{Km} / \mathrm{L}, 59,20 \mathrm{Km} / \mathrm{L}$, konsumsi bahan bakar paling hemat dihasilkan dari bahan bakar dengan penambahan bioethanol $10 \%$.

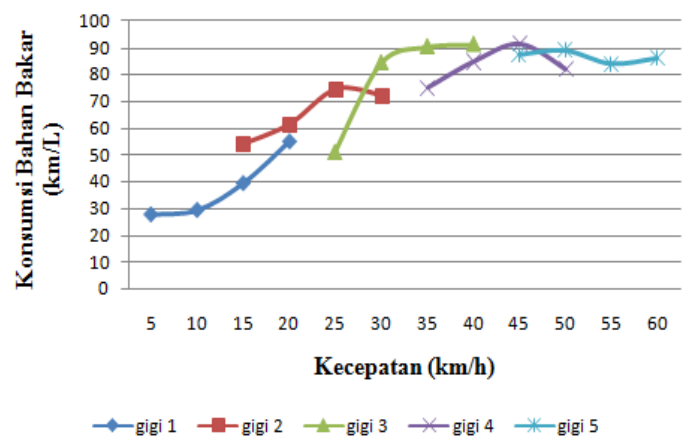

Gambar 4 Konsumsi Bahan Bakar Premium + Bioethanol 10\%

Hal ini sesuai dengan penelitian yang telah dilakukan Suhendar, et al., (2016). 
Penelitian tersebut menguji konsumsi bahan bakar premium yang di campur dengan etanol sebanyak $10 \%$ dan $20 \%$ dan di uji pada motor injeksi Yamaha Mio J.

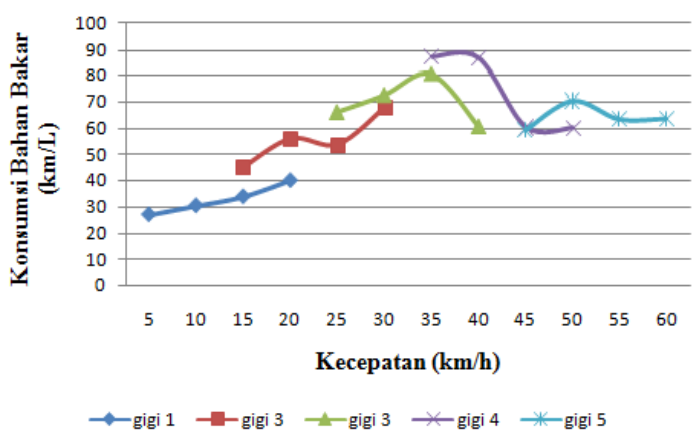

Gambar 5 Konsumsi Bahan Bakar Premium + Bioethanol 12\%

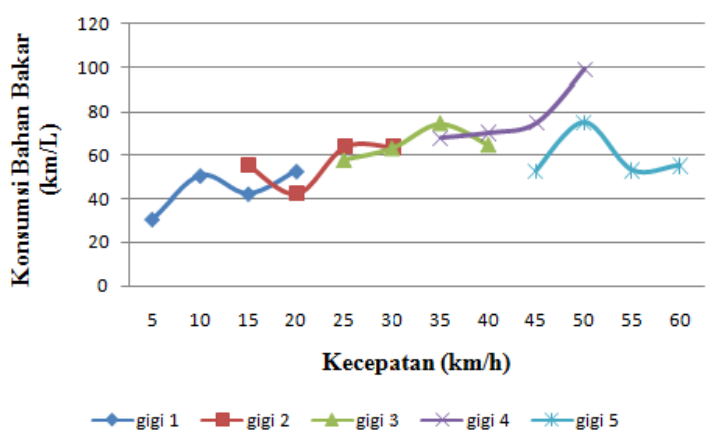

Gambar 6 Konsumsi Bahan Bakar Pertalite Murni

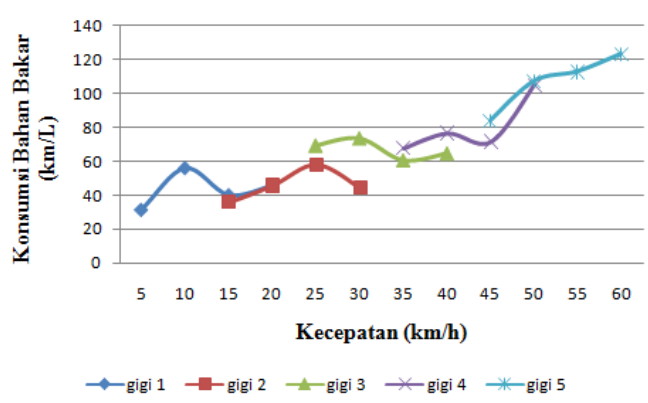

Gambar 7 Konsumsi Bahan Bakar Pertalite+Bioethanol 8\%

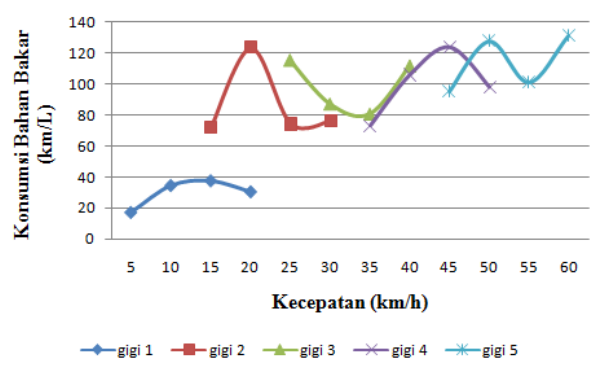

Gambar 8 Konsumsi Bahan Bakar Pertalite + Bioethanol 10\%

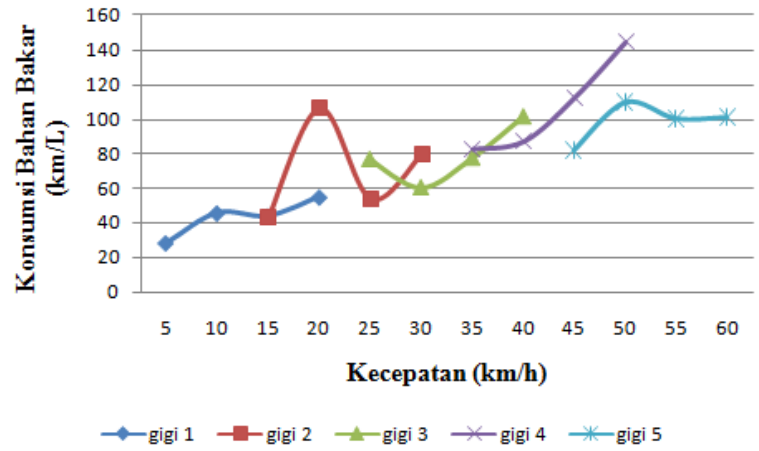

Gambar 9 Konsumsi Bahan Bakar Pertalite + Bioethanol 12\%

Dari data hasil pengujian grafik konsumsi bahan bakar Pertalite dan Pertalite campuran dapat disimpulkan bahwa bahan bakar Pertalite murni, rata-rata pada semua gigi percepatan mampu menempuh jarak $60,43 \mathrm{Km} / \mathrm{L}$, jarak yang ditempuh lebih pendek dibandingkan dengan ketiga bahan bakar Premium campuran dengan konsentrasi campuran $8 \%, 10 \%$, dan $12 \%$ bioethanol per liter Pertalite berturut-turut yaitu $68,61 \mathrm{Km} / \mathrm{L}$, $85,88 \mathrm{Km} / \mathrm{L}, 79,45 \mathrm{Km} / \mathrm{L}$.

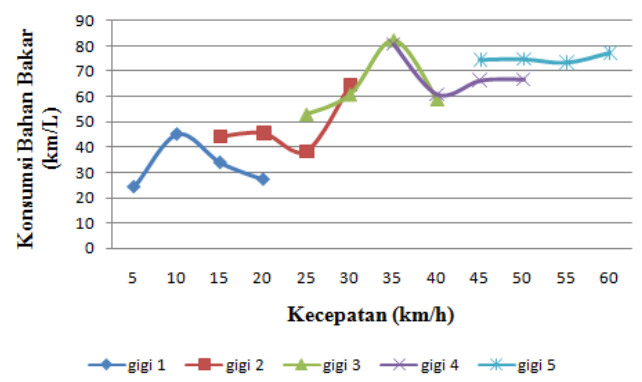

Gambar 10 Konsumsi Bahan Bakar Pertamax Murni

Konsumsi bahan bakar paling hemat dihasilkan dari bahan bakar dengan penambahan bioethanol $10 \%$. Hal ini sesuai dengan penelitian yang telah dilakukan (Wahminto,2017).

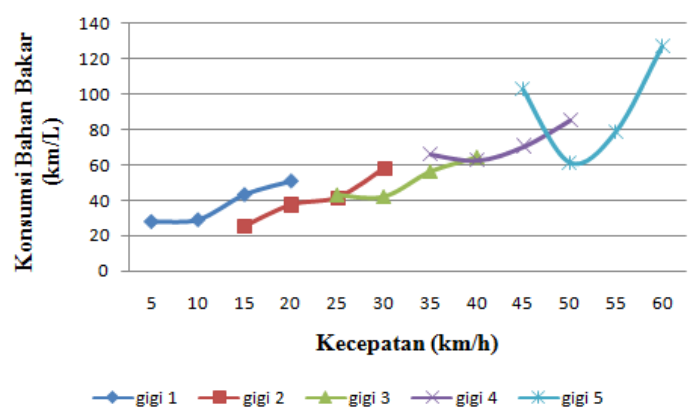

Gambar 11. Konsumsi Bahan Bakar Pertamax + Bioethanol $8 \%$ 


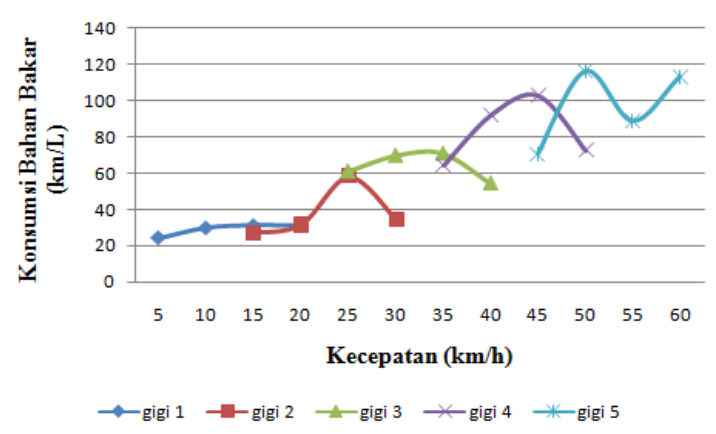

Gambar 12. Konsumsi Bahan Bakar Pertamax+ Bioethanol 10\%

Dari data hasil pengujian didapat grafik konsumsi bahan bakar Pertamax dan Pertamax campuran dapat disimpulkan bahwa bahan bakar Pertamax murni, rata-rata pada semua gigi percepatan mampu menempuh jarak $57,70 \mathrm{Km} / \mathrm{L}$, jarak yang ditempuh lebih pendek dibandingkan dengan ketiga bahan bakar Pertamax campuran dengan konsentrasi campuran $8 \%, 10 \%$, dan $12 \%$ bioethanol per liter Pertamax berturut-turut yaitu 58,72 $\mathrm{Km} / \mathrm{L}, 62,27 \mathrm{Km} / \mathrm{L}, 60,92 \mathrm{Km} / \mathrm{L}$.

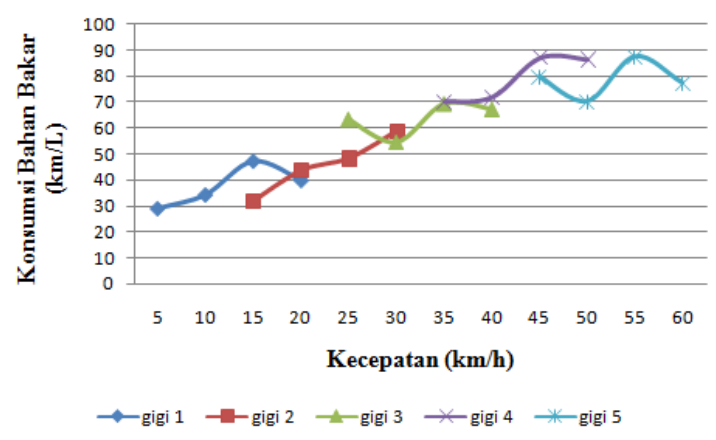

Gambar 13. Konsumsi Bahan Bakar Pertamax + Bioethanol 10\%

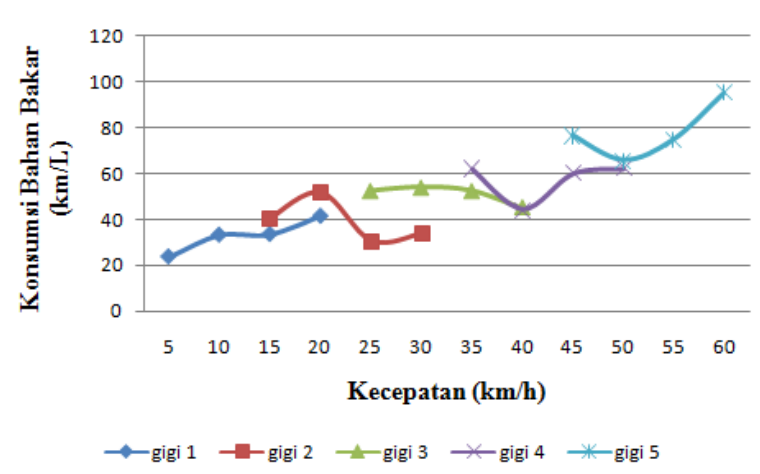

Gambar 14. Konsumsi Bahan Bakar Pertamax Turbo Murni

Jarak yang ditempuh pada penambahan bioethanol $10 \%$ paling jauh dibandingkan penambahan bioethanol $0 \%, 8 \%$ dan $12 \%$ pada rata-rata semua percepatan untuk campuran bahan bakar Pertamax bioethanol. Konsumsi bahan bakar paling hemat dihasilkan dari bahan bakar dengan penambahan bioethanol $10 \%$. Hal ini sesuai dengan penelitian yang telah dilakukan (Wahminto,2017).

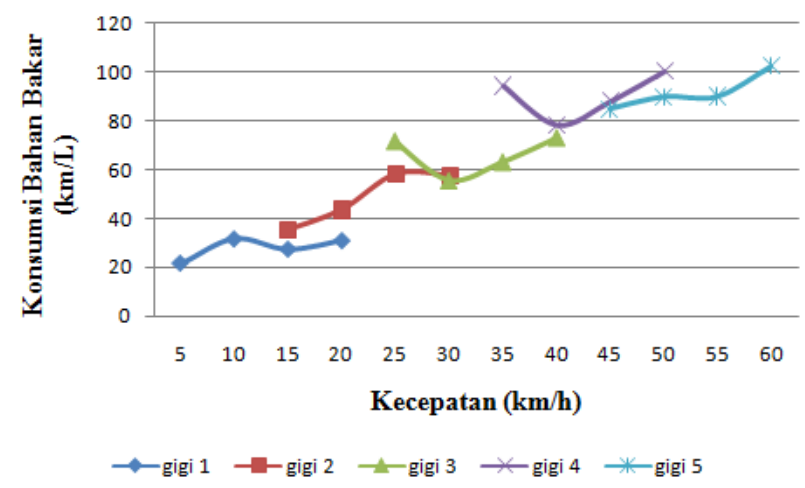

Gambar 15. Konsumsi Bahan Bakar Pertamax Turbo + Bioethanol 8\%

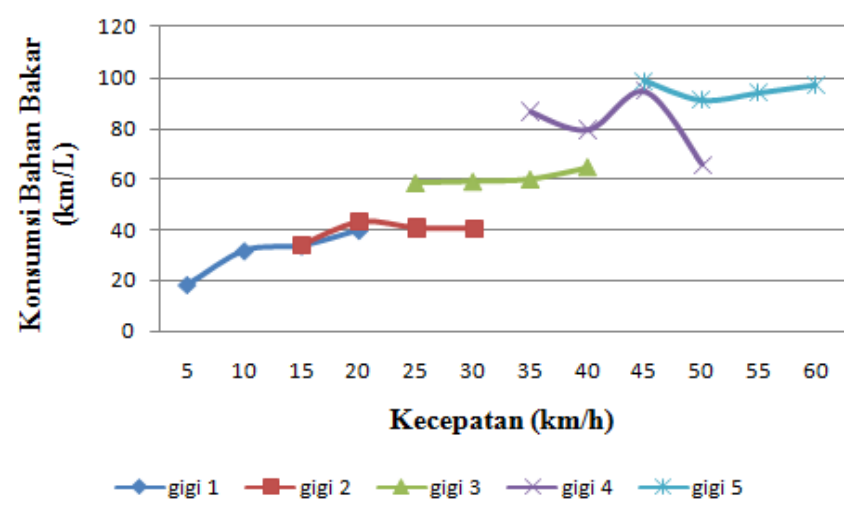

Gambar 16. Konsumsi Bahan Bakar Pertamax Turbo + Bioethanol 10\%

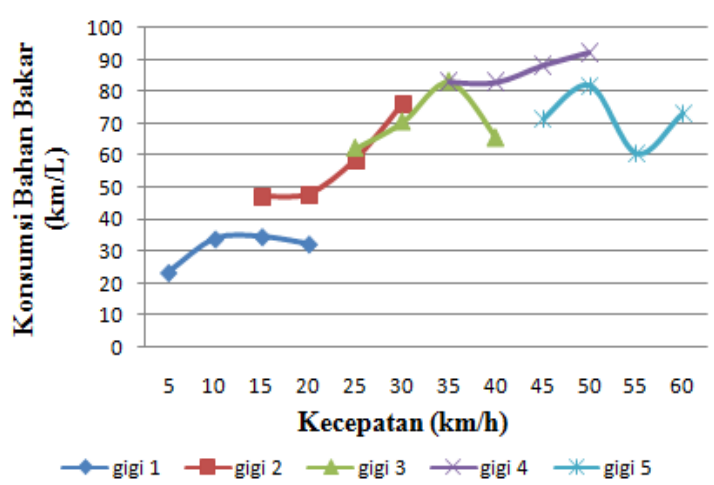

Gambar 17. Konsumsi Bahan Bakar Pertamax Turbo + Bioethanol $12 \%$

Konsumsi bahan bakar Pertamax Turbo dan Pertamax Turbo campuran dapat disimpulkan bahwa bahan bakar Pertamax 
Turbo murni, rata-rata pada semua gigi percepatan mampu menempuh jarak 51,70 $\mathrm{Km} / \mathrm{L}$, jarak yang ditempuh lebih pendek dibandingkan dengan ketiga bahan bakar Pertamax Turbo campuran dengan konsentrasi campuran $8 \%, 10 \%$, dan $12 \%$ bioethanol per liter Pertamax Turbo berturut-turut yaitu $64,87 \mathrm{Km} / \mathrm{L}, 61,47 \mathrm{Km} / \mathrm{L}, 63,48 \mathrm{Km} / \mathrm{L}$. Jarak yang ditempuh pada penambahan bioethanol $8 \%$ paling jauh dibandingkan penambahan bioethanol $0 \%, 10 \%$ dan $12 \%$ pada rata-rata semua percepatan untuk campuran bahan bakar Pertamax Turbo + bioethanol.

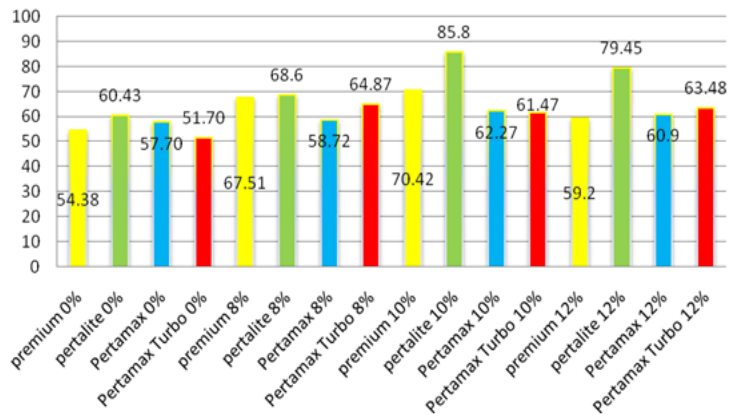

Gambar 18 Perbandingan rata-rata konsumsi BBM dengan variasi Bioethanol 8\%, $10 \%$ dan $12 \%$

Dari hasil pengujian pada grafik konsumsi bahan bakar dengan penambahan bioethanol dapat disimpulkan bahwa bahan bakar Pertamax Turbo murni, rata-rata pada semua gigi percepatan mampu menempuh jarak 51,70 Km/L, jarak yang ditempuh lebih pendek dibandingkan dengan 15 bahan bakar yang diuji yaitu (premium 0\%, Pertalite $0 \%$, Pertamax $0 \%$, premium $8 \%$, Pertalite $8 \%$, Pertamax $8 \%$, Pertamax Turbo $8 \%$, premium $10 \%$, Pertalite $10 \%$, Pertamax $10 \%$, Pertamax Turbo $10 \%$, premium $12 \%$, Pertalite $12 \%$, Pertamax 12\%, Pertamax Turbo 12\%) murni dan campuran dengan konsentrasi campuran $8 \%$, 10\%, dan $12 \%$ bioethanol per liter Pertamax Turbo berturut-turut yaitu 54.38 $\mathrm{Km} / \mathrm{L}, 60.43 \mathrm{Km} / \mathrm{L}, \quad 57.70 \mathrm{Km} / \mathrm{L}, 67.51$ $\mathrm{Km} / \mathrm{L}, 68.61 \mathrm{Km} / \mathrm{L}, 58.72 \mathrm{Km} / \mathrm{L}, 64.87$ $\mathrm{Km} / \mathrm{L}, 70.42 \mathrm{Km} / \mathrm{L}, \quad 85.88 \mathrm{Km} / \mathrm{L}, 62.27$ $\mathrm{Km} / \mathrm{L}, \quad 61.47 \mathrm{Km} / \mathrm{L}, \quad 59.20 \mathrm{Km} / \mathrm{L}, 79.45$ $\mathrm{Km} / \mathrm{L}, 60.92 \mathrm{Km} / \mathrm{L}, 63.48 \mathrm{Km} / \mathrm{L}$. Jarak yang ditempuh pada Pertalite penambahan bioethanol $10 \%$ paling jauh dibandingkan dengan bahan bakar murni dan bahan bakar dengan penambahan bioethanol 8\% dan $12 \%$ pada rata-rata semua percepatan, laju konsumsi bahan bakar paling hemat dihasilkan dari bahan bakar dengan penambahan bioethanol $10 \%$.

Makin tinggi RON pada bahan bakar maka seharusnya laju konsumsi bahan bakar lebih irit, tetapi pada hasil pengujian laju konsumsi bahan bakar pada motor Verza 150 (Fuel Injection) konsumsi bahan bakar semakin tinggi RON atau oktana data yang didapat hasil yang didapatkan turun hal ini terjadi karena seharusnya setiap jenis bahan bakar perlu adanya penyetelan pada ECU pada kendaraan, jika penyetelan ECU tidak dilakukan maka Timing pengapian tidak sesuai dengan jenis bahan bakar yang di pakai hal ini dapat menyebabkan fenomena knocking dimana piston belum sampai pada TMA bahan bakar sudah terbakar (self Ignition), peristiwa tersebut menyebabkan daya mesin yang dihasilkan akan menurun dan bahan bakarnya akan lebih boros.

\section{KESIMPULAN}

Hasil analisa pengaruh penambahan bioethanol pada bahan bakar premium, Pertalite, Pertamax, Pertamax Turbo terhadap laju konsumsi bahan bakar sepeda motor VERZA 150 cc konsumsi bahan bakar Pertalite maupun dengan penambahan bioethanol lebih hemat dibandingkan dengan bahan bakar premium, Pertamax, Pertamax Turbo maupun pada penambahan bioethanol. Dari perbandingan bahan bakar murni, campuran bioethanol $8 \%, 10 \%$, dan $12 \%$ nilai tertinggi pada bahan bakar Pertalite dengan campuran bioethanol $10 \%$ pada rata-rata semua percepatan mampu menempuh jarak $85,88 \mathrm{Km} / \mathrm{L}$.

\section{DAFTAR PUSTAKA}

Bennett, C. R., \& Greenwood, I. D., (2001). Modelling Road User and Environtmental Effect in HDM-4, Paris: The World Road Association (PIARC).

Priangkoso, T., Wildana, A., \& Setyoko., 2014. Hubungan Kecepatan Posisi Gigi dan Jenis Bahan Bakar Dengan Konsumsi Bahan Bakar Sepeda Motor, Jurnal Momentum, Vol.10, No.2, Hal. 7-11, Fakultas Teknik, Universitas Wahid Hasyim, Semarang.

PT. Pertamina (PERSERO)., 2007, Material Safety Data Sheet (Lembar Data Keselamatan Bahan), Juni 2007, 
Direktorat-Pemasaran dan

Niaga,Pertamina,Jakarta.http://www. pertamina.com/industrialfuel/media 130569/premium.pdf, diakses: 25 Desember 2018.

PT. Pertamina (PERSERO)., 2015. Material Safety Data Sheet (Lembar Data Keselamatan Bahan), April 2015, Direktorat-Pemasaran dan Niaga Pertamina,Jakarta.http://www.pertam ina.com/industrialfuel/media/30668/p ertamax.pdf, diakses: 25 Desember 2018.

Suhendar, A., Farid, A., \& Fuhaid, N., 2016. Pengaruh Pemakaian Campuran Bahan Bakar Premium Dengan Ethanol Terhadap Unjuk Kerja Motor Bakar Injeksi. Jurnal Widya Teknika, vol. 24, no. 1, hal 13-16, Fakultas Teknik, Universitas Widyagama, Malang.

Wahminto, I., 2017. Analisis Pengaruh Penambahan Bioethanol Pada Bahan Bakar Premium, Pertalite, Pertamax, Pertamax Turbo Terhadap Konsumsi Bahan Bakar Sepeda Motor Bertransmisi CVT 125cc FI (FUEL INJECTION), Tugas Akhir, T. Mesin, Fakultas Teknik, Universitas Wahid Hasyim, Semarang. 